\title{
INFLUENCE OF FAMILY BURDEN AND SOCIAL SUPPORT ON FUNCTIONAL DISABILITY IN PERSONS WITH SCHIZOPHRENIA
}

\author{
Manabendra Makhal ${ }^{1}$
}

${ }_{1}^{1}$ Assistant Professor, Department of Psychiatry, North Bengal Medical College, Sushrutanagar, West Bengal, India.

ABSTRACT
BACKGROUND
Schizophrenia causes considerable functional disability. Families are the main support system and primary care givers for persons
with schizophrenia in India. Family burden and social support are the main concern. One should get acquainted about the disability
in persons with Schizophrenia.
The present study was designed to assess the nature and severity of disability in persons with schizophrenia, perceived social
support as well as burdens among caregivers of patients and to find out the correlation of disability with family burden and
perceived social support.

\section{MATERIALS AND METHODS}

This cross-sectional study was conducted in the Institute of Postgraduate Medical Education and Research (IPGMER), Kolkata, India. One hundred patients with a clinical diagnosis of schizophrenia as per ICD-10 and their caregivers were taken. Thereafter, all patients were assessed on Indian Disability Evaluation Assessment Scale (IDEAS) for disability. Family Burden Interview ScheduleShort Form (FBIS-SF) was applied on caregivers to assess family burden. Social Support Questionnaire (SSQ) to assess the perceived social support was also applied.

\section{RESULTS}

It was found that majority of the patients were having severe level of disability in global, interpersonal activity and communication and understanding area and moderate level in work and self-care domains. FBIS-SF total score had a significant $(<0.035)$ positive correlation and SSQ total score had a significant $(\mathrm{p}<0.000)$ negative correlation with global disability. The total score of family burden and perceived social support emerged as the sole significant predictor of global disability.

\section{CONCLUSION}

Treatment of persons with schizophrenia should be focused on family burden and social support system to improve competencies in occupation, self-care and interpersonal relationship with co-workers and significant others.

\section{KEY WORDS}

Disability, Family Burden, Social Support, Schizophrenia.

HOW TO CITE THIS ARTICLE: Makhal M. Influence of family burden and social support on functional disability in persons with schizophrenia. J. Evolution Med. Dent. Sci. 2018;7(27):3086-3091, DOI: 10.14260/jemds/2018/693

\section{BACKGROUND}

The lifetime prevalence of schizophrenia is one percent globally of any given adult population. ${ }^{1,2}$ Schizophrenia is the most commonly diagnosed major mental illness among debilitating diseases which affects general health, sociooccupational functioning, autonomy, subjective well-being and life satisfaction of the patient and causes variable burden on the patient, family and community.2,3 It is the 8th leading cause of disability in people aged 15 to 44 years. Schizophrenia is a major contributor to the global burden of disease accounting for about $1 \%$ of disability-adjusted life year, $3 \%$ of year lived with disability. ${ }^{3}$ Lack of awareness about mental illness, stigma encountered by sufferers and their kin's belief in supernatural causation and traditional methods of care often make these problems more complex.

'Financial or Other Competing Interest': None.

Submission 25-05-2018, Peer Review 19-06-2018,

Acceptance 25-06-2018, Published 02-07-2018.

Corresponding Author:

Dr. Manabendra Makhal,

B-1, Medical Officer Quarters,

North Bengal Medical College,

P. O. Sushrutanagar-734012,

West Bengal, India.

E-mail:drmakhal@gmail.com

DOI: $10.14260 /$ jemds $/ 2018 / 693$
The socio-demographic parameters, negative symptoms, disruptive symptoms, frequent hospitalisations, medication side effects, long duration of untreated illness with downhill course, short duration of treatment and lack of social support have been recognised as the important factors responsible for disability in schizophrenia. ${ }^{3,4}$

According to WHO, a disability is "any restriction or lack (resulting from any impairment) of ability to perform an activity in the manner or within the range considered normal for a human being" (WHO, 1980). The level of disability is more in all chronic mental disorders compared to chronic physical illness (Shiv Goutam- 1985). Disabilities in person with schizophrenia that may result directly are poor self-care, difficulty in daily living skill, social withdrawal, problems in employment and in relationship to their social environment. The range of disability that occur depends upon the interaction of the patient with their social environment. ${ }^{5}$

About one-third of schizophrenic patients tend to become chronic leading to much disability and loss of manpower. ${ }^{6}$ But for most, it is a life long illness. About 25\% of diagnosed schizophrenics recover fully, another $50 \%$ make a partial recovery and rest $25 \%$ of cases require long-term care for their persistent and severe symptoms.6,7 Persons with psychiatric disability are usually idle in their homes and may require assistance or prompting even to do activities of daily living. This eventually poses a challenge for the caregivers 
and burdens them with additional duties of assisting the unproductive family member after discharge. ${ }^{8}$ This could deteriorate the family functioning and can even develop negative expressed emotions in primary caregivers. It may promote revolving door syndrome and ultimately poor progress in disability. This also affects the mental health system of our country. ${ }^{8}$

Family, the primary environment, might stimulate the persons with schizophrenia in reducing their disability. Perhaps the family environment could influence either in a positive or negative way based on the mutual reciprocations. In India families represent key resource persons in the care of persons with mental disorders. ${ }^{9}$ There are inadequate resource personnel to execute psychosocial interventions mainly after discharge from hospital, hence key relatives are important and can be utilised as treatment collaborators. Healthy family environment with adequate social support would be ideal for persons with schizophrenia in leading the life with optimal functioning. ${ }^{10}$ Family burden refers to a psychological state that ensues from the combination of physical work and emotional and social pressure involved in caring. According to Platt 'family burden' refers to the presence of problems, difficulties or adverse events which affect the life of the person with mental disorders and patients' significant others. ${ }^{11}$ Although, the entire family experiences the burden of illness, a major part of the responsibility is often shouldered by one "primary caregiver" who experiences physical and emotional burden.

It has been documented that up to 83 percent of the friends and family members of person with schizophrenia experience considerable financial, emotional and practical burdens. They report time lost from work, unreimbursed medical and other patient-related expenses, limited time for leisure and socialising, elevated symptoms of psychological distress and feelings of stigmatisation. In addition to its impact on caregiver quality of life, care-giving strain has been associated with other adverse effects including poorer selfrated health, chronic medical conditions or both; increased visits to a primary care physician; greater use of psychotropic drugs such as tranquilizers and antidepressants; and increased risk of medical hospitalisation. ${ }^{12-14}$

Review of literature in Indian ${ }^{12,13}$ and in International scenario ${ }^{14}$ highlights the family burden in schizophrenia as a major issue compared to other mental illness. The evidence based data arouses major concern as disability in persons with schizophrenia and caregivers coping skills required to be enhanced for better care giving process. A recent study showed deficit in the areas of social functioning have a significant negative correlation with social support system. ${ }^{15}$ Baker et al (1992) have shown that psychiatric patients with high and sustained social support have higher life satisfaction over time. ${ }^{16}$ Healthy family environment with maintained high level of social support would be ideal for persons with schizophrenia for better community living with adequate functioning. The recent studies suggest that disability in persons with schizophrenia as well as caregivers coping skills can be improved for better care giving and better functioning of the subject. ${ }^{17}$ Caregiver's high active coping skill as well as high social support has been repeatedly linked to low levels of family burden (Magliano, Fadden, Economou et al, 2000; Potasznik and Nelson, 1984; Solomon and Draine, 1995). ${ }^{18,19}$
As per our knowledge, there are few studies on disability in schizophrenia and its correlation with family burden and perceived social support. Assessment of disability and its correlation with perceived social support and family burden can help us to develop measures for lessening family burden, improving social support for the better living of the subjects.

\section{MATERIALS AND METHODS}

\section{Study Design and Settings}

This cross-sectional, hospital-based study was conducted over a period of one year in the Institute of Postgraduate Medical Education and Research (IPGMER), Kolkata, India. IPGMER is a multispeciality teaching cum tertiary care hospital providing services to a major area of eastern part of India.

\section{Aim}

Aim of the study was to assess the nature and severity of disability in persons with schizophrenia, perceived social support as well as burdens among caregivers of patients.

\section{Sample Size and Sampling}

All consecutive subjects aged between 18 and 59 years, of either genders attending the outpatient department of psychiatry of the institute, fulfilling the criteria of schizophrenia as per the International Classification of Diseases, $10^{\text {th }}$ version, Classification of Mental and Behavioural Disorders ${ }^{20}$ were taken up for the study with their consent. Purposive sampling method was used in this study. Total one hundred subjects and their caregivers were enrolled within one-year convenient study period. The primary caregivers were interviewed. Patients with diagnoses of schizoaffective disorder, other co-morbid psychiatric disorders, substance use disorders, personality disorders, mental retardation, organic brain syndrome and chronic debilitating physical illnesses were excluded from the index study. Thereafter, all patients were assessed on IDEAS (Indian Disability Evaluation Assessment Scale) for disability, Social Support Questionnaire (SSQ) for perceived social support and Family Burden Interview Schedule- Short Form (FBIS-SF) for family burden.

\section{Research Instruments}

Indian Disability Evaluation Assessment Scale (IDEAS) ${ }^{21}$

In 2001, the Rehabilitation Committee of the Indian Psychiatric Society took on the responsibility of developing a task for assessing and qualifying psychiatric disability and this Indian Disability Evaluation and Assessment Scale (IDEAS) was born. It has now been gazetted by the ministry of Human Resources and Empowerment, Government of India as the recommended instrument. IDEAS have four items: self-care, interpersonal activities (social relationships), communication and understanding and work. Each item is scored between 0 and 4, i.e. from no disability to profound disability. The MI 2Y-score for the duration of illness was given as: $<2$ years $=1 ; 2-5$ years $=2 ; 6-10$ years $=3 ;>10$ years $=4$. The global disability $=$ total disability score + MI $2 \mathrm{Y}$ score. The percentage of global disability scores as follows: Score $0=$ no $(0 \%)$ disability; Score $1-7=$ mild $(<40 \%)$ disability; Score 8 - 13= moderate $(40-70 \%)$ disability; score $14-19=$ severe $(71-99 \%)$ disability; score $20=$ profound $(100 \%)$ disability. 


\section{Social Support Questionnaire (SSQ) ${ }^{22}$}

It is an Indian adaptation (Nehra et al, 1998), of the Pollack and Harris Scale (Pollack and Harris, 1993) to measure perceived social support. It has 18 items. A higher score indicates more perceived social support. The items in the scale refer to help, concern, support, reinforcement and criticism that a person gets from one's family, friends, social acquaintances and working colleagues. It is a dependable instrument in terms of both consistency and stability of scores. It can be used in a variety of situations where the perceived social support is required as an independent, dependent or intervening variable. It has a test-retest reliability of 0.59 and correlation with clinician's assessment at 0.80 and with items of social support from Family Interaction Pattern Scale (Bhatti et al, 1986) at 0.65.

\section{Family Burden Interview Schedule- Short Form (FBIS- SF) 23}

The Family Burden Interview Schedule- Short Form (FBIS/SF) is adapted from the Toolkit for Evaluating Family Experience with Severe Mental Illness by Richard Tessler and Gail Gamache in 1994. The FBIS/SF takes a multi-dimensional approach and distinguishes different aspects of burden from one another. There are 65 items, which include five modules related to the negative aspects of caregiving: (1) Assistance with the activities of daily life; (2) Supervision of bothersome or troublesome behaviours; (3) Impact on daily routines; (4) Financial expenditures and (5) Worry on daily routines.

\section{Statistical Analysis}

Descriptive analysis was computed in terms of mean and standard deviation for continuous variables and frequency with percentage for ordinal and nominal variables. Correlation analysis of different level of disability with Family Burden and Perceived Social Support was done using Pearson's product moment and Spearman's rank order correlation. Multivariate (linear regression) analysis using the enter method was used to study the effect of Perceived Social Support and Family Burden (independent variables) on global disability. For all statistical analyses, $\mathrm{p}<0.05$ (2-tailed) was considered to be statistically significant. The statistical package for social sciences (SPSS) version 16.0 was used for the analysis of the data of this study.

\section{RESULTS}

The sample consisted of 58 men (58\%) and 42 women (42\%). The socio-demographic profile revealed that majority (35\%) of the subjects in this study fell within the age range of 30 - 39 with the mean age of 32.75 (SD=9.373). 19\% were illiterate and $42 \%$ were educated up to primary school. While $44 \%$ of the subjects were single (unmarried, widow/widower, divorced or separated), $56 \%$ were married.
Most of the patients were unemployed (38\%). 57\% of the subjects belonged to rural domicile and $43 \%$ were from urban domicile. Majority (62\%) of the subjects had per capita income below Rs. 600.00 with sample's mean per capita income of Rs. 667.44 per month (SD= 543.80). Majority (51\%) of patients had 2 - 5 years of total illness duration, of which majority (27\%) had severe level of disability. $71 \%$ patients received treatment for 1 - 5 years. Parents were the primary caregivers in most (45\%) of the cases.

It was found that majority (57\%) of the patients were having severe level of disability in global, interpersonal activity and communication and understanding areas. Only $2 \%$ and $6 \%$ patients had mild and profound global level of disability respectively. Disability in work and self-care domains were moderately affected in majority of the patients (63\% and 55\% respectively). Mean perceived social support was 43.02 ( $\mathrm{SD}=6.173$ ) (Table 1 and 2).

Most of the patients needed assistance (51\%) and supervision $(90 \%)$ in daily living once or twice in a week. Financial burden for maintaining treatment and not doing any work was seen once or twice in a week among $84 \%$ caregivers (Table 3).

Strong correlation of global disability and its different domains (self-care, interpersonal activity, communication and understanding, works and MI2Y) with perceived social support and family burden was found. Perceived social support and global disability were negatively correlated. Different domains of disability are also significantly (negatively) correlated with SSQ total score. Positive correlation of family burden with global as well as some domains of disability was also seen (Table 4). No correlation of global and other domains of disability with sociodemographic (viz. age) and clinical profile (viz. total duration of illness) was found.

To study the effect of independent variables on disability, linear regression with enter method was performed. For this, all the variables (viz. SSQ total score and FBIS-SF score) that had shown significant correlation with any of the domains of IDEAS were considered as independent variables and scores on the Global score on IDEAS was considered as dependent variables. The findings were interpreted as the percentage variance accounted for in the dependent variable by the independent variables alone and in combination, and by examining the partial correlations of the residuals [variables removed from analysis as they failed to achieve significant predictive power (e.g. significance level < 0.05)] accounted for in the dependent variable by the independent variables with the dependent variable. The total score of Family Burden (FBIS-SF) and Perceived Social Support (SSQ) total score emerged as the sole significant predictor of Global disability (Table 5).

\begin{tabular}{|c|c|c|}
\hline Socio-Demographic and Clinical Profile & Mean & Std. Deviation \\
\hline Age (years) & 32.75 & 9.373 \\
\hline Total duration of illness (years) & 6.73 & 5.115 \\
\hline Total duration of treatment received (years) & 4.19 & 2.390 \\
\hline Per capita income (INR) & 667.44 & 543.805 \\
\hline Social Support Questionnaires Total Scores & 43.02 & 6.173 \\
\hline Disability domain according to IDEAS & Mean & Std. Deviation \\
\hline IDEAS: Self care & 2.33 & .726 \\
\hline IDEAS: Interpersonal activities & 2.67 & .620 \\
\hline IDEAS: Communication and understanding & 2.61 & .723 \\
\hline
\end{tabular}




\begin{tabular}{|c|c|c|}
\hline IDEAS: Works & 2.27 & .694 \\
\hline IDEAS: MI2Y (month of illness in last 2 years) & 3.91 & .452 \\
\hline IDEAS: Global & 13.79 & 2.434 \\
\hline FBIS-SF: Assistance in daily living & 44.14 & 9.877 \\
\hline FBIS-SF: Supervision & 28.98 & 7.441 \\
\hline FBIS-SF: Financial expenditures & 17.45 & 2.560 \\
\hline FBIS-SF: Impact on daily living & 14.59 & 3.715 \\
\hline FBIS-SF: Worry & 18.64 & 3.647 \\
\hline FBIS-SF: Total & 123.56 & 15.936 \\
\hline \multicolumn{3}{|c|}{$\begin{array}{c}\text { Table 1. Showing Socio-Demographic profile, Clinical profile, domains of Disability, } \\
\text { perceived Social support and Family Burden }\end{array}$} \\
\hline
\end{tabular}

\begin{tabular}{|c|c|c|c|c|c|}
\hline $\begin{array}{c}\text { Count (\% of Total) } \\
\mathbf{n = 1 0 0}\end{array}$ & Self-Care & Interpersonal Activity & $\begin{array}{c}\text { Communication } \\
\text { and Understanding }\end{array}$ & Works & Global \\
\hline Mild disability & $09(09 \%)$ & $03(03 \%)$ & $08(08 \%)$ & $09(09 \%)$ & $02(02 \%)$ \\
\hline Moderate disability & $55(55 \%)$ & $34(34 \%)$ & $29(29 \%)$ & $62(62 \%)$ & $35(35 \%)$ \\
\hline Severe disability & $30(30 \%)$ & $57(57 \%)$ & $57(57 \%)$ & $23(23 \%)$ & $57(57 \%)$ \\
\hline Profound disability & $06(06 \%)$ & $06(06 \%)$ & $06(06 \%)$ & $06(06 \%)$ & $06(06 \%)$ \\
\hline Total & $\mathbf{1 0 0}(\mathbf{1 0 0} \%)$ & $\mathbf{1 0 0}(\mathbf{1 0 0} \%)$ & $\mathbf{1 0 0}(\mathbf{1 0 0} \%)$ & $\mathbf{1 0 0 ( 1 0 0 \% )}$ & $\mathbf{1 0 0}(\mathbf{1 0 0} \%)$ \\
\hline \multicolumn{7}{|r}{} \\
\hline
\end{tabular}

\begin{tabular}{|c|c|c|c|c|c|}
\hline $\begin{array}{c}\text { Count (\% of Total) } \\
\text { n= 100 }\end{array}$ & $\begin{array}{c}\text { Assistance in } \\
\text { Daily Living }\end{array}$ & Supervision & $\begin{array}{c}\text { Impact on Daily } \\
\text { Routine }\end{array}$ & Worry & $\begin{array}{c}\text { Financial Burden during } \\
\text { Past 12 Months }\end{array}$ \\
\hline $\begin{array}{c}\text { Never or less than once in a } \\
\text { week }\end{array}$ & $03(03 \%)$ & $03(03 \%)$ & $01(01 \%)$ & $37(37 \%)$ & $04(04 \%)$ \\
\hline 1 to 2 times in a week & $51(51 \%)$ & $90(90 \%)$ & $33(33 \%)$ & $53(53 \%)$ & $84(84 \%)$ \\
\hline 3 to 6 times in a week & $34(34 \%)$ & $07(07 \%)$ & $49(49 \%)$ & $07(07 \%)$ & $09(09 \%)$ \\
\hline Every day in a week & $12(12 \%)$ & $00(00 \%)$ & $17(17 \%)$ & $03(03 \%)$ & $03(03 \%)$ \\
\hline Total & $\mathbf{1 0 0 ( 1 0 0 \% )}$ & $\mathbf{1 0 0}(\mathbf{1 0 0} \%)$ & $\mathbf{1 0 0}(\mathbf{1 0 0} \%)$ & $\mathbf{1 0 0}(\mathbf{1 0 0} \%)$ & $\mathbf{1 0 0}(\mathbf{1 0 0} \%)$ \\
\hline \multicolumn{7}{|c|}{ Table 3. Showing Frequency of Nature and Severity of Family Burden } \\
\hline
\end{tabular}

\begin{tabular}{|c|c|c|c|c|c|c|c|}
\hline \multicolumn{2}{|c|}{ Variables } & \multicolumn{5}{c|}{ Disability in IDEAS } \\
\cline { 2 - 8 } & Self-Care & $\begin{array}{c}\text { Interpersonal } \\
\text { Activities }\end{array}$ & $\begin{array}{c}\text { Communication and } \\
\text { Understanding }\end{array}$ & Works & MI2Y & Global \\
\hline \multirow{2}{*}{$\begin{array}{c}\text { Perceived Social } \\
\text { Support }\end{array}$} & $\begin{array}{c}\text { Pearson } \\
\text { Correlation }\end{array}$ & $-0.356^{* *}$ & $-0.299^{* *}$ & $-0.301^{* *}$ & $-0.329^{* *}$ & -0.104 & $-0.385^{* *}$ \\
\cline { 2 - 8 } & Sig. (2-tailed) & 0.000 & 0.003 & 0.002 & 0.001 & 0.301 & 0.000 \\
\hline \multirow{2}{*}{ Family Burden } & $\begin{array}{c}\text { Pearson } \\
\text { Correlation }\end{array}$ & 0.005 & $0.210^{*}$ & $0.211^{*}$ & 0.204 & 0.560 & $0.211^{*}$ \\
\cline { 2 - 8 } & Sig. (2-tailed) & 0.963 & 0.036 & 0.035 & 0.073 & 0.065 & $0.036^{*}$ \\
\hline \multirow{2}{*}{$\begin{array}{l}\text { Table 4. Correlation among Global Disability and its different Domains (Self-Care, Interpersonal Activities, Communication } \\
\text { and Understanding, Works, MI2Y) with perceived Social Support and Family Burden }\end{array}$} \\
\hline
\end{tabular}

${ }^{* *}$ Correlation is significant at the 0.01 level (2-tailed), *Correlation is significant at the 0.05 level (2-tailed).

\begin{tabular}{|c|c|c|c|c|c|c|c|}
\hline Predictor & B value & Std. Error & $\boldsymbol{\beta}$ (Beta) & $\mathbf{R}^{\mathbf{2}}$ value & $\begin{array}{c}\text { Adjusted } \\
\mathbf{R}^{\mathbf{2}} \text { value }\end{array}$ & F value & Significance \\
\hline Constant & 14.67 & 2.57 & & 0.22 & 0.19 & 8.90 & 0.000 \\
\hline Perceived Social Support & -0.16 & 0.04 & -0.42 & & & 0.000 \\
\hline Family Burden Table 5. Predictor of Global Disability- Regression Analysis by Enters Method & 0.016 \\
\hline
\end{tabular}

\section{DISCUSSION}

Functional disability in schizophrenia has been found to be affected by characteristics like age of onset, duration of illness, severity and type of symptoms, duration of untreated psychosis, cognitive deterioration and intellectual functioning. ${ }^{4}$ Socio-demographic profile of the current study sample is typical of the population attending the psychiatric outpatient department of a tertiary level institution of our country. ${ }^{24}$ Either the early onset of the illness or the deterioration in functioning could be the reasons why majority did not go for higher education. The subjects were found to be unfit to express their needs for marriage due to their disability. Disability in the self-care domain was found to be a barrier to get married for majority. Impact of the illness on the individuals' functioning was found to be the reasons for divorce or separation. The impact of the disability was one of the main causes of unemployment. Their disabilities either prevented them from doing jobs or discontinued their job.

Irrespective of the setting, most of the schizophrenic patients have moderate disability. ${ }^{25}$ My study was also similar that most of the patients included in the study were having severe level of disability in global, interpersonal activity and communication and understanding domains and moderate level of disability in self-care and work domain of IDEAS (Table 2). 
Most (51\%) of the patients with schizophrenia having duration of illness between 2 - 5 yrs. had moderate-to-severe disability in this study, which is similar with the study of Indra et al (2005). ${ }^{26}$ Thara and Joseph (1995) found that the socio-demographic and clinical variables like gender, age of onset, mode of onset, duration of illness and pre-morbid functioning which are related to course and outcome have also been reported to have an effect on disability. ${ }^{27}$ My study did not find out such relation, as it is a cross-sectional study.

There was a statistically significant strong negative correlation (even after regression analysis) between global disability score and SSQ score in my study (Table 4 and 5). More similar findings also observed in the study of Caron et al (2005).28

Family burden total score and the sub-scores were all correlated with WHO-DAS scores at a significant level in the study of Ertugrul et al (2002). In our index study, a statistically significant strong positive correlation was also found between global disability score and FBIS-SF total score. 29,30

In the index study, a good percentage of variance in the entire sample remained unaccounted for. Based on the review of literature, it is obvious that there are many other variables e.g. subtype of schizophrenia, duration of untreated psychosis, side effect of pharmacotherapy, type and adequacy of treatment that may influence the disability in schizophrenia. However, it was beyond the scope of the present study to include all of these.

The present study is not without limitations and the same should be considered while interpreting the results. Small sample size, absence of longitudinal assessment and purposive sampling could yield type II errors. The results of this clinic based study are not generalisable to community settings. Further longitudinal studies with larger sample size including many other variables which were unaccounted to be done to assess their effects on disability in patients with schizophrenia.

\section{CONCLUSION}

Disability in persons with schizophrenia has been found to be influenced proportionately by family burden and inversely by perceived social support. Psychosocial interventions should be focused on enhancing individual competencies for occupation, maintaining self-care, keeping better interpersonal relationship with co-workers and significant others.

\section{ACKNOWLEDGEMENTS}

The author is grateful to Professor Divya Gopal Mukherjee, Professor and Head, Department of Psychiatry, RG Kar Medical College, Kolkata, India, for his help and guidance during the study.

\section{REFERENCES}

[1] RC Kessler, Chiu WT, Demler 0, et al. Prevalence, severity and comorbidity of 12-month DSM-IV disorders in the national comorbidity survey replication. Archives of General Psychiatry 2005;62(6):617-27.
[2] Jablensky A. Epidemiology of schizophrenia: the global burden of disease and disability. European Archives of Psychiatry \& Clinical Neuroscience 2000;250(6):27485.

[3] Jablensky A, Sartorius N, Ernberg G, et al. Schizophrenia: manifestations, incidence and course in different cultures. A World Health Organization tencountry study. Psychol Med Monogr Suppl 1992;20:197.

[4] Alptekin K, Erkoc S, Gogus AK, et al. Disability in schizophrenia: clinical correlates and prediction over 1-year follow-up. Psychiar Res 2005;135(2):103-11.

[5] Shihabuddeen TMI, Gopinath PS. Group meetings of care takers of patients with Schizophrenia and Bipolar mood disorder. Indian J Psychiatry 2005;47(3):153-6.

[6] Bleuler M. Schizophrenic deterioration. 1. $\mathrm{Br}$ J Psychiatry 1983;143:78-9.

[7] Varghese M, Shah A, Kumar UGS. Family intervention and support in Schizophrenia: A Manual on Family Intervention for the Mental Health Professional. Version 2. WHO/NIMHANS, 2002.

[8] Shihabuddeen ITM, Mehar H, Pinto DA. Disability in schizophrenia and bipolar mood disorder in general hospital psychiatry unit. Delhi Psychiatry Journal 2011;14(2):258-61.

[9] Shihabuddeen ITM, Mehar H. Daycare center attached GHPU: the felt need in India for comprehensive mental healthcare services. Indian J Psychol Med 2008;30(2):80-2.

[10] Cuijpers P. The effects of family interventions on relatives' burden: a meta-analysis. Journal of Mental Health 1999;8(3):275-85.

[11] Platt S. Measuring the burden of psychiatric illness on the family. An evaluation of some rating scales. Psychol Med 1985;15(2):383-93.

[12] Pai S, Kapur RL. The burden of a family of a psychiatric patient: development of an interview schedule. $\mathrm{Br} \mathrm{J}$ Psychiatry 1981;138:332-5.

[13] Shihabuddeen ITM, Mehar H. Overcoming barriers to integrate psychosocial services to mainstream mental health practices in India. Int J Multidisci Educ Res 2012;1(1):246-50.

[14] Perlick DA, Rosenheck RA, Kaczynski R, et al. Components and correlates of family burden in schizophrenia. Psychiatr Serv 2006;57(8):1117-25.

[15] Ali RM, Bhatti RS. Social support system and family burden due to chronic schizophrenia in rural and urban background. Indian J Psychiatry 1988;30(4):349-53.

[16] Baker F, Jodrey D, Intagliata J. Social support and quality of life of community support clients. Community Mental Health Journal 1992;28(5):397411.

[17] Scazufca M, Kuipers E. Coping strategies in relatives of people with schizophrenia before and after psychiatric admission. The British Journal of Psychiatry 1999;174:154-8.

[18] Solomon P, Draine J. Subjective burden among family members of mentally ill adults: relation to stress, coping and adaptation. American Journal of Orthopsychiatry 1995;65(3):419-27. 
[19] Solomon Z, Mikulincer M, Avitzur E. Coping, locus of control, social support and combat-related posttraumatic stress disorder: a prospective study. Journal of Personality and Social Psychology 1988;55(2):279-85.

[20] World Health Organization. The International Classification of Disease, Classification of Mental and Behavioral Disorders, 10th revision, Geneva, 2006.

[21] Thara R. Indian Disability Evaluation and Assessment Scale (IDEAS). The Rehabilitation Committee of the Indian Psychiatric Society 2002.

[22] Nehra R, Kulhara P, Verma SK. Manual for PGI Social Support Questionnaire, Department of Psychiatry, Post Graduate Institute of Medical Education and Research, Chandigarh, 1-8, Rupa Psychological Centre, Varanasi, India, 1998.

[23] Tessler T, Gamache G. Family burden interview schedule - short form. 1994:258-63.

[24] Shah R, Kulhara P, Grover S, et al. Relationship between spirituality/religiousness and coping in patients with residual schizophrenia. Qual Life Res 2011;20(7):1053-60.
[25] Parker G, Hadzi-Pavlovic D. The capacity of a measure of disability (the LSP) to predict hospital readmission in those with schizophrenia. Psychol Med 1995;25(1):157-63.

[26] Mohan I, Tandon R, Kalra $H$, et al. Disability assessment in mental illnesses using Indian Disability Evaluation Assessment Scale (IDEAS). Indian Journal of Medical Research 2005;121(6):759-63.

[27] Thara R, Joseph AA. Gender difference in symptoms and course of schizophrenia. Indian J Psychiatry 1995;37(3):124-8.

[28] Caron J, Lecomte Y, Stip E, et al. Predictors of quality of life in schizophrenia. Community Mental Health Journal 2005;41(4):399-417.

[29] Ochoa S, Vilaplana M, Haro JM, et al. Do needs, symptoms or disability of outpatients with schizophrenia influence family burden? Soc Psychiatry Psychiatr Epidemiol 2008;43(8):612-8.

[30] Ertuğrul A, Uluğ B. The influence of neuro-cognitive deficits and symptoms on disability in schizophrenia. Acta Psychiatrica Scandinavica 2002;105(3):196-201. 